BMJ

Open

Gastroenterology

\section{Risk of lower gastrointestinal bleeding and colorectal neoplasms following initiation of low-dose aspirin: a Danish population-based cohort study}

To cite: Troelsen FS, Farkas DK, Erichsen R, et al. Risk of lower gastrointestinal bleeding and colorectal neoplasms following initiation of low-dose aspirin: a Danish population-based cohort study. BMJ Open Gastro 2020;7:e000453. doi:10.1136/ bmjgast-2020-000453

- Additional material is published online only. To view please visit the journal online (http://dx.doi.org/10.1136/ bmjgast-2020-000453).

Received 25 May 2020 Revised 3 July 2020 Accepted 4 July 2020
(A) Check for updates

(c) Author(s) (or their employer(s)) 2020. Re-use permitted under CC BY-NC. No commercial re-use. See rights and permissions. Published by BMJ.

Department of Clinical Epidemiology, Aarhus University Hospital, Aarhus N, Denmark

Correspondence to Mrs Frederikke Schønfeldt Troelsen; frtroe@clin.au.dk

\section{ABSTRACT}

Objective Aspirin may increase the risk of lower gastrointestinal bleeding (LGIB) from precursors of colorectal cancer (CRC). We investigated whether use of low-dose aspirin, through initiation of LGIB, may lead patients to undergo colonoscopy and polypectomy before manifest CRC.

Design We conducted a historical cohort study (2005-2013) of all Danish residents who initiated low-dose aspirin treatment $(n=412202)$ in a setting without screening for CRC. Each new aspirin user was matched with three non-users ( $n=1236560$ ) by age, sex and region of residence on the date of their matched new user's first-time aspirin prescription (index date). We computed absolute risks (ARs), risk differences and relative risks (RRs) of LGIB, lower gastrointestinal endoscopy, colorectal polyps and CRC, comparing aspirin users with non-users.

Results The ARs were higher for new users than non-users for LGIB, lower gastrointestinal endoscopy, colorectal polyps and CRC within 3 months after index. Comparing new users with non-users, the RRs were 2.79 (95\% Cl 2.40 to 3.24 ) for LGIB, 1.73 (95\% Cl 1.63 to 1.84) for lower gastrointestinal endoscopy, 1.56 (95\% Cl 1.42 to 1.72$)$ for colorectal polyps and $1.73(95 \% \mathrm{Cl} 1.51$ to 1.98) for CRC. The RRs remained elevated for more than 12 months after the index date, with the exception of $\mathrm{CRC}$ where the RRs were slightly decreased during the 3-5years (RR $0.90,95 \% \mathrm{Cl} 0.83$ to 0.98 ) and more than 5 years (RR $0.91,95 \% \mathrm{Cl} 0.82$ to 1.00 ) following the index date.

Conclusion These findings indicate that aspirin may contribute to reduce CRC risk by causing premalignant polyps to bleed, thereby expediting colonoscopy and polypectomy before CRC development.

\section{INTRODUCTION}

Colorectal cancer (CRC) remains the most frequently diagnosed gastrointestinal cancer worldwide. ${ }^{1}$ Early detection and removal of precancerous polyps can prevent subsequent CRC development. ${ }^{2-7}$ The possibility of preventing CRC development through
Summary box

What is already known about this subject?

- Long-term continuous use of low-dose aspirin is associated with a decreased risk of colorectal cancer (CRC).

- Although the existing evidence has been conflicting some studies suggested that aspirin use could be associated with an increased sensitivity of faecal occult blood testing for detecting colorectal neoplasms, possibly explained by an increased risk of gastrointestinal bleeding.

What are the new findings?

- Initiation of aspirin might contribute to a lower risk of CRC by promoting bleeding from colorectal polyps and leading patients to undergo colonoscopy with polypectomy before manifest CRC.

How might it impact on clinical practice in the foreseeable future?

- The potential of aspirin to increase the detection of premalignant polyps by triggering early gastrointestinal bleeding may have major public health importance, given the growing number of faecal blood test-based CRC screening programmes.

polypectomy highlight the need to improve detection of prevalent CRC precursors.

Previous studies showed an inverse association between long-term continuous aspirin use and CRC risk. ${ }^{8-14}$ Underlying mechanisms are thought to include inhibition of polyp development mediated by reduced prostaglandin production. ${ }^{1516}$ However, other mechanisms are also plausible. Globally, the number of CRC screening programmes based on faecal occult blood testing is growing. ${ }^{17-19}$ Concurrently, the burden of cardiovascular disease creates a substantial need to prevent cardiovascular events among the older population. ${ }^{20}$ Low-dose aspirin is, therefore, frequently prescribed in the target population for CRC screening $^{21-26}$ and several previous studies 
have examined the performance of faecal occult blood tests in detecting colorectal neoplasms among aspirin users. However, they have had conflicting findings. ${ }^{27-33}$ Some studies suggested that aspirin use is associated with a decreased positive predictive value (PPV) of faecal occult blood testing. ${ }^{28303133}$ A randomised trial published in 2019 reported no increase in the sensitivity of faecal occult blood testing for detecting colorectal neoplasms in aspirin users compared with a placebo group. ${ }^{32}$ In contrast, other studies showed an increased sensitivity of the test for detecting colorectal neoplasms among aspirin users, ${ }^{2729}$ possibly explained by an increased risk of gastrointestinal bleeding. ${ }^{34-36}$ However, no prior study has investigated the potential of low-dose aspirin to prevent CRC by causing prevalent premalignant colorectal polyps to bleed and thereby expediting colonoscopy and polypectomy before CRC manifests. We, therefore, conducted a cohort study in Denmark to examine the incidence of lower gastrointestinal bleeding (LGIB), lower gastrointestinal endoscopy, colorectal polyps and CRC following a first-time prescription for low-dose aspirin, in order to investigate whether aspirin use may promote detection of precancerous polyps before CRC development.

\section{METHODS}

\section{Setting and data sources}

We used prospectively collected data for the period 1 January 2005 to 30 November 2013 obtained from the Danish National Health Service Prescription Database (DNHSPD), the Danish National Patient Registry (DNPR), the Danish National Pathology Registry (DPR) and the Danish Cancer Registry (DCR) to conduct this population-based matched historical cohort study. The Danish Civil Registration System assigns a permanent civil registration number (CRN) to each Danish resident at the time of birth or immigration and also monitors the occurrence of death and emigration from Denmark. ${ }^{37} 38$ Through use of CRNs, we were able to perform unambiguous linkage between the registries. ${ }^{39}$ All Danish residents are covered by the tax-supported Danish healthcare system. ${ }^{40}$ CRC screening was not performed routinely in Denmark during the study period.

The DNHSPD contains complete data on all reimbursed prescriptions dispensed from community pharmacies and hospital-based outpatient pharmacies in Denmark since 2004. ${ }^{41}$ The DNPR contains records on all hospital inpatient stays since $1977 .{ }^{42}$ Since 1995 , the DNPR also has included hospital outpatient visits and contacts with emergency rooms. DNPR data include the CRN for each patient, dates of hospital admission and discharge, surgical procedures (including endoscopies and polypectomies), and up to 20 discharge diagnoses, coded according to the International Classification of Diseases (ICD). Since 1996 surgical procedures have been coded using a Danish version of the Nordic Medico-Statistical Committee (NOMESCO) Classification of Surgical procedures. ${ }^{42}$ The DPR contains detailed nationwide records of all pathology specimens examined since 1997. Data are coded according to the Systematised Nomenclature of Medicine (SNOMED) ${ }^{43}$ The DCR has maintained records on all incident malignant neoplasms diagnosed in Denmark since 1943. Cancers are coded using ICD-10. ${ }^{44}$

\section{New users of low-dose aspirin}

We identified all new users of low-dose aspirin from the DNHSPD. New users were defined as individuals who redeemed a first-time prescription for low-dose aspirin (in strengths of 75,100 or $150 \mathrm{mg}$ ) recorded in the DNHSPD during the 2005-2013 period. Drug codes are listed in online supplementary table 1 . Individuals who redeemed a prescription for low-dose aspirin before 1 January 2005 were not considered to be new users. While low-dose aspirin is available over-the-counter in Denmark, approximately $90 \%$ of patients who use it on a continuous basis obtain a prescription to reduce costs. ${ }^{45} \mathrm{New}$ aspirin users with a diagnosis of inflammatory bowel disease (IBD) recorded in the DNPR prior to their first-time prescription for aspirin were excluded, in order to minimise the number of patients under potential endoscopic surveillance. Similarly, we excluded new users with a previous or concomitant diagnosis of CRC recorded in the DCR before the date of their first-time aspirin prescription.

\section{Matched comparison cohort}

We matched each new aspirin user with three individuals from the general population who were alive and who had no prescriptions for low-dose aspirin or records of CRC or IBD prior to the date of their matched new user's firsttime prescription for low-dose aspirin (defined as the index date). Matching criteria were age ( \pm 5 years), sex and region of residence in Denmark on the index date. Non-users were sampled with replacement. ${ }^{46}$ In the event that matched non-users redeemed a prescription for lowdose aspirin during the study period, their follow-up time was terminated and they joined the new user cohort. In total, 161865 (13.1\%) subjects from the matched cohort redeemed an aspirin prescription after the index date.

\section{Outcomes}

We examined time to the following outcomes: (1) LGIB, (2) lower gastrointestinal endoscopy, (3) colorectal polyps and (4) CRC. For each outcome, patients with a record of the given outcome before the index date were excluded (ie, when LGIB was the outcome, we excluded individuals with LGIB before the index date, etc). We excluded $4836(1.2 \%)$ new users with a diagnosis of LGIB, 57195 (13.9\%) new users recorded as having had a lower gastrointestinal endoscopy and 16787 (4.1\%) new users who received a diagnosis of colorectal polyps before the index date.

\section{LGIB and lower gastrointestinal endoscopy}

Data on LGIB and lower gastrointestinal endoscopies were obtained by using the CRN to link new users and 
non-users to the DNPR (procedure codes are listed in online supplementary table 1$)$.

\section{Colorectal polyps}

Using DPR data during 2005-2012, we obtained information on endoscopically detected colorectal polyps. Polyps were categorised according to location, as follows: proximal to the splenic flexure (cecum through the transverse colon); distal to the splenic flexure (splenic flexure through the sigmoid colon), and rectal. We additionally categorised polyps as conventional adenomas (tubular, villous, tubulovillous or flat) and serrated polyps (hyperplastic polyps, sessile serrated polyps or traditional serrated adenomas). If polyp diagnoses were absent in the DPR, we searched the DNPR using ICD-10 codes for polyps and NOMESCO codes for endoscopically performed polypectomies (codes are listed in online supplementary table 1).

\section{Colorectal cancer}

Data on incident CRC were obtained from the DCR. ${ }^{44}$ Like colorectal polyps, CRCs were categorised according to location and further according to TNM stage ${ }^{47}$ at diagnosis: localised (T1-4, N0, M0), regional (Tx, N1-3, M0), metastatic (Tx, Nx, M1) or unknown (T2-4, N0,x, M0,x) cancers (codes are listed in online supplementary table $1)$.

\section{Covariates}

Based on all records available in the DNPR from 1977 until the index date, we obtained information on the following hospital diagnoses potentially associated with use of low-dose aspirin and risk of LGIB, lower gastrointestinal endoscopy, colorectal polyps or CRC: alcoholism-related disorders, chronic liver disease, chronic obstructive pulmonary disease, haemorrhoids, diverticular disease, obesity and diabetes mellitus (codes are listed in online supplementary table 1). We obtained information on the following prescription redemptions recorded in the DNHSPD within 1year prior to the index date: non-aspirin non-steroidal antiinflammatory drugs (NSAIDs), high-dose aspirin, postmenopausal hormone replacement therapy, statins, corticosteroids, insulin and analogues, oral antidiabetic drugs, other antithrombotic treatments, calcium channel blockers and ACE inhibitors (drug codes are listed in online supplementary table 1). We also used Charlson Comorbidity Index (CCI) scores as a measure of the burden of comorbidity. ${ }^{48}$ The CCI is a scoring system that assigns from one to six points to a range of diseases as components of a summed aggregate score (codes and diagnoses are listed in online supplementary table 2). Patients were categorised into three subgroups according to their calculated CCI score: low (no comorbidities $)=$ CCI score of 0 , medium $=$ CCI score of $1-2$ or high=CCI score of 3 or more.

\section{Statistical analyses}

Absolute and relative risks

We followed new users and non-users from the index date until the first occurrence of a given outcome (LGIB, lower gastrointestinal endoscopy, colorectal polyps or CRC) in addition to death, emigration or 30 November 2013. Separate analyses were conducted for each outcome. We calculated the absolute risk of the outcomes as the cumulative incidence proportion during 3 months, $3 \leq 12$ months and more than 12 months after the index date in new users and non-users, respectively. Death was considered a competing risk. We also calculated cumulative risk differences (RDs) as the difference between the absolute risks in new users minus non-users. Using bootstrapping, we calculated $95 \%$ CIs associated with the RDs.

We used Cox proportional hazards regression analysis to compute HRs with associated $95 \%$ CIs as an estimate of the relative risk (RR) of the outcomes, comparing new users of low-dose aspirin with their matched nonusers. As for the absolute risks, time elapsed since the index date was considered as the underlying time scale. However, we also calculated RRs of CRC within 1-3 years, $3-5$ years and $5+$ years after the index date, in addition to the previously defined intervals. We constructed two separate multivariable models, adjusted for potential confounders of the association between low-dose aspirin initiation and (1) LGIB and lower gastrointestinal endoscopy and (2) colorectal polyps and CRC based on existing literature. ${ }^{89-64}$ Model 1 included CGI score on the index date, index year, presence of alcoholism-related disorders, haemorrhoids and diverticular disease recorded at any time before the index date, as well as records of prescriptions other than low-dose aspirin (including NSAIDs, high-dose aspirin, postmenopausal hormone replacement therapy, statins, corticosteroids, insulin and analogues, oral antidiabetic drugs, other antithrombotic treatments, calcium channel blockers and ACE inhibitors) redeemed within 1 year prior to the index date. Model 2 included CCI score on the index date, index year, presence of alcoholism-related disorders, chronic liver disease, chronic obstructive pulmonary disease, diverticular disease and diabetes mellitus recorded at any time before the index date, as well as records of prescriptions for medications other than low-dose aspirin (including NSAIDs, high-dose aspirin, postmenopausal hormone replacement therapy, statins, corticosteroids, insulin and analogues, oral antidiabetic drugs, other antithrombotic treatments, calcium channel blockers and ACE inhibitors) redeemed within 1 year prior to the index date. Potential confounding from age, sex and region of residence were controlled through matching. We stratified absolute risks and RRs by age, gender, modified CCI score, index year, comorbidities and records of prescriptions for medications other than low-dose aspirin redeemed within 1 year prior to the index date. To investigate whether presence of LGIB and removal of colorectal polyps could be intermediate steps on the pathway from initiation of low- dose aspirin to decreased CRC risk, we additionally stratified 
our analysis of colorectal polyp risk by presence of LGIB recorded within 1 year prior to polypectomy. We further stratified the risk of CRC by polypectomy recorded within 1 year after the index date.

\section{Prevalence ratios}

Using the robust Poisson method, we calculated prevalence ratios (PRs) with associated 95\% CIs to compare the prevalence of new aspirin users and non-users with records of specific combinations of the different outcomes during the study period.

\section{Sensitivity analysis}

To evaluate if use of other antithrombotic treatments (see online supplementary table 1 for codes) impacted the risk of LGIB and colorectal neoplasms, we conducted a sensitivity analysis excluding patients with prescriptions for other antithrombotic treatments redeemed within 1 year prior to the index date.

Data management and statistical analyses were performed using SAS statistical software V.9.4 (SAS Institute).

\section{RESULTS}

\section{Characteristics}

We identified 422318 individuals recorded in the DNHSPD as having a first-time prescription redemption for low-dose aspirin during 2005-2013. We excluded 3568 $(0.8 \%)$ individuals with IBD and $6098(1.4 \%)$ individuals with a previous diagnosis of CRC. Finally, 450 new aspirin users were excluded due to unknown region of residence on the index date. For 23 new aspirin users, fewer than three possible non-users could be identified. The final cohort thus comprised 412202 new users of low-dose aspirin and 1236560 non-users matched by age (median age $=66$ years (IQR: $58-75$ years $)$, sex $($ men $=52 \%)$ and region of residence on the index date (table 1 ).

New users were more likely than non-users to have a medium CCI score $(39.9 \%$ vs $21.4 \%)$ or high CCI score $(10.7 \%$ vs $4.8 \%$ ) (table 1 and online supplementary table 3). New users also were more likely than non-users to have redeemed a prescription for NSAIDs $(29.2 \%$ vs $22.6 \%)$, statins $(46.4 \%$ vs $11.5 \%)$, oral antidiabetic drugs $(10.6 \%$ vs $3.7 \%)$, other antithrombotic treatments $(16.6 \%$ vs $4.2 \%)$, calcium channel blockers $(21.9 \%$ vs $11.1 \%$ ) or ACE inhibitors (27.9\% vs $11.6 \%$ ) within 1 year prior to the index date. The remaining characteristics were similarly distributed between new users and nonusers (table 1).

\section{Lower gastrointestinal bleeding}

In total, 5977 new users of low-dose aspirin received a diagnosis of LGIB during the follow-up, yielding low absolute risks during all three follow-up periods (figure 1). Among non-users, 8472 persons received a diagnosis of LGIB, yielding absolute risks below $1.5 \%$ during $3,3 \leq 12$ and more than 12 months after the index date (figure 1). The corresponding RDs are illustrated in figure 1 . New users of low-dose aspirin were at increased RR of LGIB compared with matched non-users during the complete follow-up period (figure 2). We observed the greatest risk increase during the first 3 months following the index date (RR 2.79, $95 \%$ CI 2.40 to 3.24). The RR decreased with time elapsed since the index date, concluding at $1.60(95 \%$ CI 1.52 to 1.67$)$ after more than 12 months of follow-up (figure 2).

\section{Lower gastrointestinal endoscopy}

New users of low-dose aspirin were more likely than nonusers to be referred for a lower gastrointestinal endoscopy. The absolute risks and RDs are outlined in figure 1. New users were more frequently referred for a lower gastrointestinal endoscopy than non-users, particularly during the first 3 months following the index date (RR $1.73,95 \%$ CI 1.63 to 3.24 ) (figure 2 ).

\section{Colorectal polyps}

Among the 39274 persons with at least one diagnosis of colorectal polyps, 12814 were new users of low-dose aspirin and 26460 were non-users. New users had a slightly higher risk of polyps than non-users (figure 1). We observed an increased RR of colorectal polyps in new users compared with non-users (figure 2). The greatest increase in RR was observed during the first 3 months of follow-up (RR 1.56, 95\% CI 1.42 to 1.72) (figure 2). The RR decreased with time elapsed since the index date, reaching 1.20 (95\% CI 1.17 to 1.24 ) after more than 12 months of follow-up. When the analysis was restricted to histologically verified polyps, new users had an elevated risk of conventional adenomas (RR 1.47, 95\% CI 1.23 to 1.77) and a particularly increased risk of serrated polyps (RR 1.77, 95\% CI 1.36 to 2.29) during the 3 months following the index date (online supplementary table 4). After stratification by polyp location, new users had a particularly increased risk of distal lesions during 3 months following the index date, compared with nonusers (RR 1.98, 95\% CI 1.39 to 2.80) (online supplementary table 4$)$. However, increased RRs were observed for all polyp locations within $3 \leq 12$ months after index date. Stratification by LGIB recorded within 1 year prior to the diagnosis of polyps yielded a substantially elevated increased risk of endoscopically removed polyps for new users within 3 months after index date (RR 2.02, 95\% CI 1.68 to 2.43$)$.

\section{Colorectal cancer}

The absolute risks and RDs of CRC among new users and non-users are illustrated in figure 1 . Of all new users diagnosed with CRC during follow-up, 3388 (71.5\%) were still receiving aspirin therapy at the time of their diagnosis. The RR of CRC was increased during the first 3 months of follow-up (RR $1.73,95 \%$ CI 1.51 to 1.98) (figure 2). We observed no substantial differences in CRC risk between the two groups during three to 12 months following the index date (RR $1.12,95 \%$ CI 1.02 to 1.23 ) or more than 12 months following the index date (RR 0.95 , 95\% CI 
Table 1 Characteristics of new users of low-dose aspirin and non-users matched by age, gender and region of residence, Denmark, 2005-2013

\begin{tabular}{|c|c|c|}
\hline & New users & Non-users \\
\hline Characteristic & $(n=412202)$ & $(n=1236560)$ \\
\hline Median age at index date $\left(\mathrm{IQR}^{\star}\right)$ & $66.2(57.7-75.5)$ & $66.2(57.7-75.5)$ \\
\hline \multicolumn{3}{|l|}{ Sex } \\
\hline Female & $195900(47.5)$ & $587688(47.5)$ \\
\hline Male & $216302(52.5)$ & $648872(52.5)$ \\
\hline \multicolumn{3}{|l|}{ Age } \\
\hline $0-49$ years & $46197(11.2)$ & $138920(11.2)$ \\
\hline 50-69years & 205601 (49.9) & $616865(49.9)$ \\
\hline $70+$ years & $160404(38.9)$ & $480775(38.9)$ \\
\hline \multicolumn{3}{|l|}{ Calendar period } \\
\hline 2005-2007 & $175482(42.6)$ & $526430(42.6)$ \\
\hline 2008-2010 & $144071(34.9)$ & $432195(34.9)$ \\
\hline 2011-2013 & $92649(22.5)$ & $277935(22.5)$ \\
\hline \multicolumn{3}{|l|}{ Charlson Comorbidity Index score } \\
\hline None (0) & $203891(49.5)$ & $913082(73.8)$ \\
\hline Medium (1-2) & $164290(39.9)$ & 264557 (21.4) \\
\hline High (3+) & $44021(10.7)$ & $58921(4.8)$ \\
\hline Alcoholism-related disorders & $13731(3.3)$ & $25187(2.0)$ \\
\hline \multicolumn{3}{|l|}{ Chronic liver disease } \\
\hline Mild & $4648(1.1)$ & $8877(0.7)$ \\
\hline Moderate to severe & $1141(0.3)$ & $2758(0.2)$ \\
\hline Chronic obstructive pulmonary diseases & $22403(5.4)$ & $38854(3.1)$ \\
\hline Haemorrhoids & $17441(4.2)$ & $44612(3.6)$ \\
\hline Diverticular disease & $13324(3.2)$ & $30651(2.5)$ \\
\hline Diabetes mellitus & $32453(7.9)$ & $34796(2.8)$ \\
\hline Obesity & $16222(3.9)$ & $23175(1.9)$ \\
\hline \multicolumn{3}{|l|}{ Concomitant drugs $\ddagger$} \\
\hline Non-aspirin NSAIDs & $120438(29.2)$ & $279208(22.6)$ \\
\hline High-dose aspirin & $72(0.0)$ & $106(0.01)$ \\
\hline Hormone replacement therapy & $33237(8.1)$ & $90033(7.3)$ \\
\hline Statins & $191455(46.4)$ & $142884(11.5)$ \\
\hline Corticosteroids & $32517(7.9)$ & $65344(5.3)$ \\
\hline Insulin and analogues & $15252(3.7)$ & $14713(1.2)$ \\
\hline Oral antidiabetic drugs & $43537(10.6)$ & $45777(3.7)$ \\
\hline Antithrombotic treatment§ & $68521(16.6)$ & $52101(4.2)$ \\
\hline Vitamin K-antagonists & $25037(6.1)$ & $41963(3.4)$ \\
\hline Heparins & $1195(0.3)$ & $902(0.1)$ \\
\hline Thienopyridines & $38758(9.4)$ & $9043(0.7)$ \\
\hline Thrombine inhibitors & $926(0.2)$ & $1124(0.1)$ \\
\hline Factor $\mathrm{X}$ inhibitors & $100(0.0)$ & $121(0.0)$ \\
\hline Nucleotide/nucleoside analogues & $5170(1.2)$ & $33(0.0)$ \\
\hline Calcium channel blockers & $90133(21.9)$ & $137077(11.1)$ \\
\hline ACE inhibitors & $115160(27.9)$ & $144009(11.6)$ \\
\hline
\end{tabular}

*IQR.

†Excluding colorectal cancer from the index (date of first-time prescription for low-dose aspirin).

†Prescription redemption within 1 year prior to the index date.

$\S$ Vitamin-K-antagonists (warfarin, phenprocoumon), heparins (dalteparin, tinzaparin, enoxaparin, heparin), thienopyridines (dipyridamole, clopidogrel, prasugrel), factor $\mathrm{X}$ inhibitors (rivaroxaban, apixaban, fondaparinux), nucleotide/nucleoside analogues (ticagrelor, congrelor).

NSAID, non-steroidal anti-inflammatory drug. 


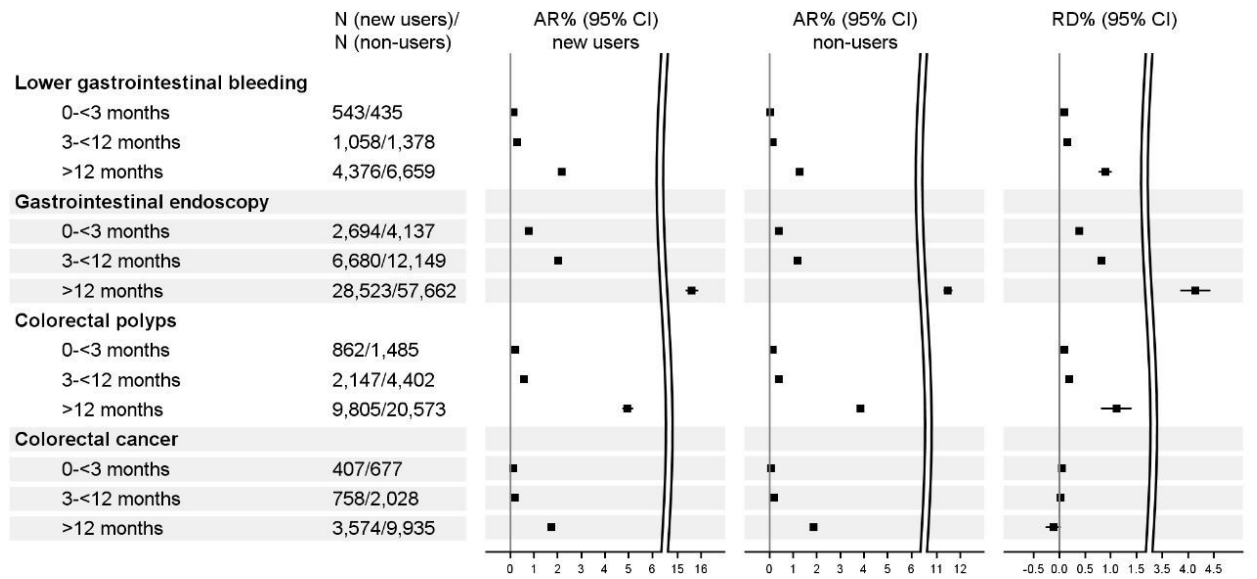

Figure 1 Cumulative incidence proportions (ARs) and cumulative risk differences (RDs) in percentages and associated 95\% Cls of lower gastrointestinal bleeding, gastrointestinal endoscopy, colorectal polyps ${ }^{\mathrm{a}}$, and colorectal cancer among new users

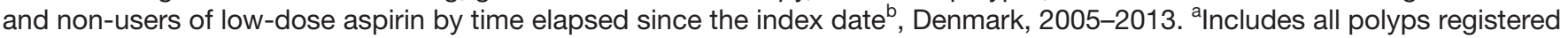
in the Danish National Pathology Registry during 2005-2012 (identified using Systemised Nomenclature of Medicine codes) or in the Danish National Patient Registry during 2005-2013 (identified using the International Classification of Diseases, 10th Revision codes or Nordic Medico-statistical Committee system codes). ${ }^{b}$ Date of first-time prescription for low-dose aspirin. ARs, absolute risks.

0.91 to 0.99 ). Overall, we observed the same pattern when we stratified the analysis by location and stage of CRC (online supplementary table 4). The risk of CRC was similar among new users and non-users during 1-3 years of follow-up (RR $1.00,95 \%$ CI 0.93 to 1.06 ), but slightly decreased during 3-5 years of follow-up (RR $0.90,95 \%$ CI 0.83 to 0.98 ) and more than 5 years of follow-up (RR 0.91 , $95 \%$ CI 0.82 to 1.00 ) after the index date (table 2). Stratification by removal of colorectal polyps recorded within 1 year following the index date yielded a decreased RR of
CRC for new users compared with non-users (RR 0.52, $95 \%$ CI 0.05 to 5.53 ).

\section{Prevalence ratios}

Table 3 presents the PRs of combinations of recorded diagnoses and procedures of specific interest for our study hypothesis. Of specific interest, the prevalence of combined LGIB, lower gastrointestinal endoscopy and colorectal polyps without CRC was substantially elevated (PR 2.32, 95\% CI 2.11 to 2.54) in new users. The

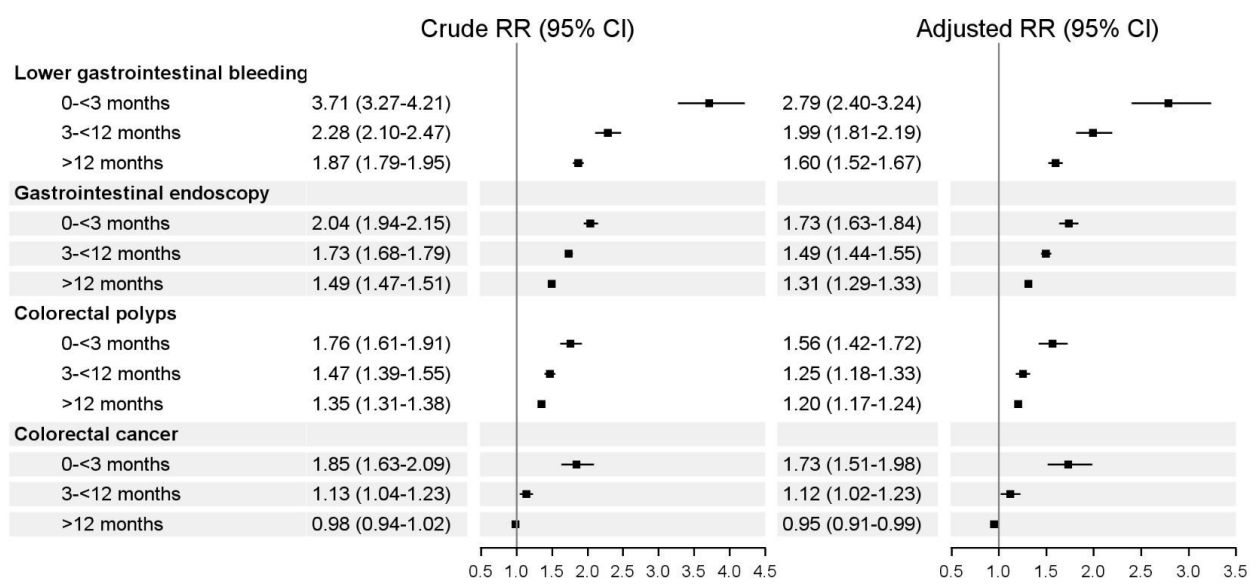

Figure 2 Crude and adjusted $^{a}$ relative risks (RRs) and associated 95\% Cls of lower gastrointestinal bleeding, gastrointestinal endoscopy, colorectal polyps ${ }^{b}$ and colorectal cancer, comparing new users with non-users of low-dose aspirin by time elapsed since the index date ${ }^{c}$, Denmark 2005-2013. ${ }^{a}$ For lower gastrointestinal bleeding and gastrointestinal endoscopy: adjusted for index year, Charlson Comorbidity Index score, alcoholism-related disorders, haemorrhoids, diverticular disease and prescriptions for other medications (including NSAIDs, statins, corticosteroids, other antithrombotic treatments and calcium channel blockers) redeemed within 1 year prior to the index date. For colorectal polyps and colorectal cancer: adjusted for index year, Charlson Comorbidity Index score, alcoholism-related disorders, chronic liver disease, chronic obstructive pulmonary disease, diverticular disease, diabetes mellitus and prescriptions for other medications (including NSAIDs, hormone replacement therapy, statins, oral antidiabetic drugs, insulin and ACE inhibitors) redeemed within 1 year prior to the index date. ' Includes all polyps registered in the Danish National Pathology Registry during 2005-2012 (identified using Systemised Nomenclature of medicine codes) or in the Danish National Patient Registry during 2005-2013 (identified using the International Classification of Diseases, 10 th Revision codes or Nordic Medico-statistical Committee system codes). ${ }^{\circ}$ Date of first-time prescription for low-dose aspirin. NSAIDs, non-steroidal anti-inflammatory drugs. 


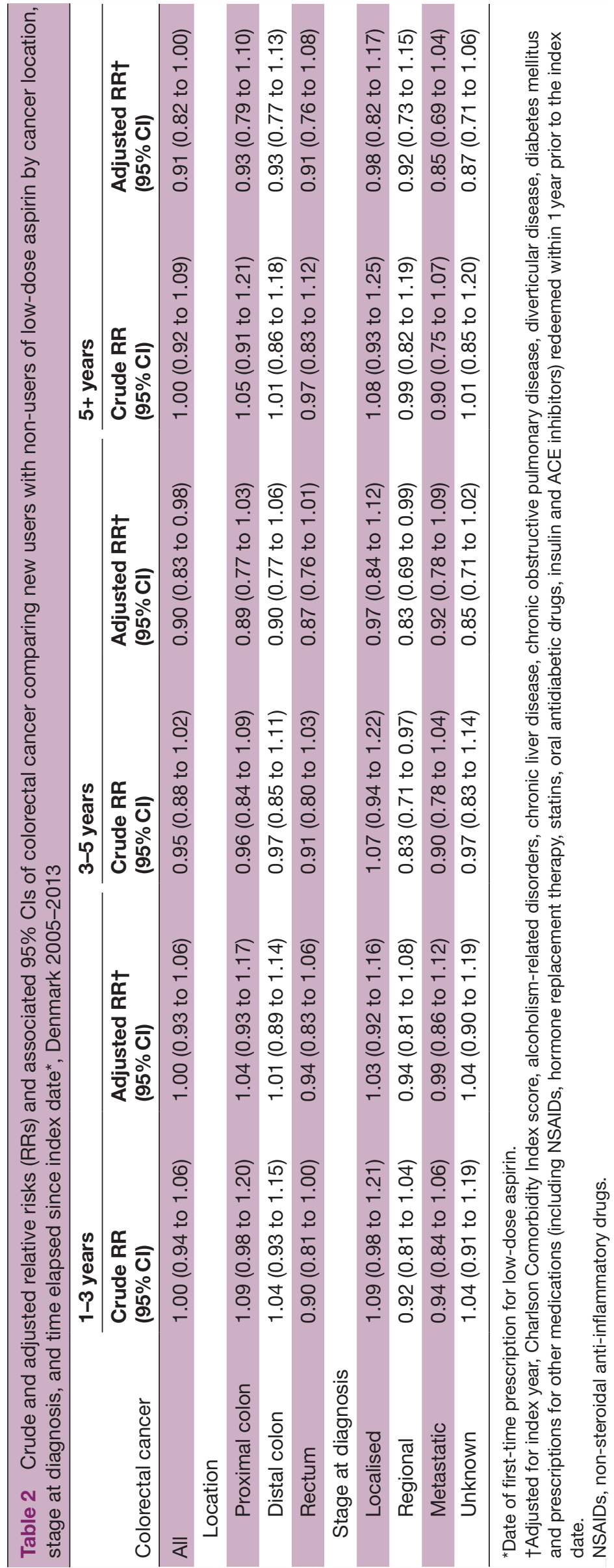


Table 3 Number of patients, proportions and prevalence ratios (PRs) with associated 95\% Cls of specific combinations of outcomes comparing new users of low-dose aspirin and their matched comparisons, Denmark 2005-2013

\begin{tabular}{|c|c|c|c|}
\hline Specific combinations of outcomes & $\begin{array}{l}\mathrm{N}(\%) \text { new users of } \\
\text { low-dose aspirin }\end{array}$ & $\begin{array}{l}\text { N (\%) non-users of } \\
\text { low-dose aspirin }\end{array}$ & PR $(95 \% \mathrm{Cl})$ \\
\hline Lower gastrointestinal bleeding & $5977(1.5)$ & $8472(0.7)$ & 2.12 (2.04 to 2.20$)$ \\
\hline $\begin{array}{l}\text { Combined records of lower gastrointestinal bleeding, } \\
\text { endoscopy and colorectal polyps }{ }^{\star}\end{array}$ & $1165(0.3)$ & $1584(0.1)$ & $2.29(2.10$ to 2.50$)$ \\
\hline $\begin{array}{l}\text { Combined records of lower gastrointestinal bleeding, } \\
\text { endoscopy and colorectal cancer without records of } \\
\text { colorectal polyps }\end{array}$ & $210(0.1)$ & $327(0.0)$ & 2.00 (1.64 to 2.44$)$ \\
\hline
\end{tabular}

*Includes all polyps registered in the Danish National Pathology Registry during 2005-2012 (identified using Systemised Nomenclature of Medicine codes) or in the Danish National Patient Registry during 2005-2013 (identified using the International Classification of Diseases, 10th Revision codes or Nordic Medico-statistical Committee system codes).

prevalence of new users without LGIB who underwent an endoscopy and were diagnosed with colorectal polyps was slightly elevated (PR 1.48, 95\% CI 1.44 to 1.52 ).

\section{Sensitivity analysis}

The results of our sensitivity analysis to evaluate the impact of other antithrombotic treatments were not materially different from our main analysis (data are not shown).

\section{DISCUSSION}

Compared with non-users, new users of low-dose aspirin had an increased RR of LGIB, colorectal polyps and CRC within 3 months following their first-time prescription for low-dose aspirin. These remained elevated for more than 12 months after the first-time prescription for low-dose aspirin. An exception was that aspirin use was associated with a slightly decreased RR of CRC starting 3 years after the first-time prescription. Finally, our results suggested that LGIB and polypectomy could be intermediate steps on the pathway from aspirin initiation to CRC prevention.

To the best of our knowledge, this large populationbased cohort study is the first to evaluate whether lowdose aspirin can promote bleeding from CRC precursors and thereby bring patients to medical attention before CRC manifests. At the same time, our findings are in line with previous findings. First and not surprisingly, we confirmed that aspirin users had an increased risk of LGIB. ${ }^{35}{ }^{36}$ As recommended by clinical guidelines, patients with LGIB should undergo colonoscopy following the bleeding episode.$^{65}{ }^{66}$ Our study indicated that a substantial proportion of new aspirin users subsequently underwent an endoscopy and thereby increased their likelihood of being diagnosed with colorectal polyps. This also was observed in our previous crosssectional study of new users of low-dose aspirin with LGIB, as well as in earlier studies investigating the role of aspirin in the performance of faecal occult blood tests for CRC screening. ${ }^{27} 2967$ First, a German study showed that use of low-dose aspirin was associated with markedly improved diagnostic performance of immunochemical faecal occult blood tests for detecting advanced colorectal neoplasms in the target population for CRC screening. ${ }^{27}$ Additionally, a cross-sectional database study suggested an increased sensitivity for detecting adenomatous polyps and CRC among users of low-dose aspirin. ${ }^{29}$ Still, other observational studies and a randomised trial indicated that daily use of low-dose aspirin was associated with a lower or comparable PPV of faecal occult blood tests for detecting CRC and its precursors, compared with nonusers and a placebo group, respectively. ${ }^{28} 3233$

We observed a slightly decreased risk of CRC in aspirin users compared with matched non-users starting 3 years after a first-time aspirin prescription. In light of the increased risk of colorectal polyps among aspirin users as described above, we speculate that aspirin use may have led to increased detection and removal of CRC precursors-possibly by triggering LGIB-and thereby helped to prevent the subsequent development of CRC. Our analysis of the risk of colorectal polyps stratified by presence of LGIB before the polyp diagnosis also suggested that LGIB is an intermediate step in the pathway between aspirin initiation and polyp detection. Similarly, our analysis of CRC risk stratified by presence of histologically verified polyps indicated that polypectomy could lead to a decreased risk of CRC in aspirin users compared with 
non-users. Finally, the increased risk of distal lesions in aspirin users during 3 months after the index date adds further support to our hypothesis as bleeding from distal lesions may be more visual for patients and clinicians thereby leading patients to medical attention.

Possible enhanced detection of premalignant polyps driven in part by temporary use of low-dose aspirin could have major clinical importance regarding CRC screening programmes. However, it is challenging to distinguish this potential mechanism from the preventive effect of longterm (at least 3 years) use of aspirin, previously demonstrated by two randomised double-blind trials. ${ }^{10}{ }^{12}$ It also should be noted that our findings conflict with those of a 2019 German randomised trial. ${ }^{32}$ That study showed similar sensitivities of faecal immunochemical testing for detecting advanced colorectal neoplasms in aspirin non-users and in patients who received a single dose of low-dose aspirin before their faecal test and in aspirin non-users. The conflicting results might be explained by the different study populations ( $78 \%$ of the included patients in the German study were referred for primary CRC screening colonoscopy).

Strengths of our study include its large sample size and population-based design in a setting of universal tax-funded healthcare, as well as the use of prospectively collected and validated registry data. ${ }^{40} 4244454868$ The ICD-10 coding for LGIB in the DNPR has previously been validated showing a PPV of $96 \%$ for fresh bleeding per rectum. ${ }^{69}$ However, several factors must be considered in interpreting our results. First, we were unable to distinguish the long-term molecular effect of aspirin suggested by previous studies ${ }^{1516}$ from the hypothesis investigated in our study. At the same time, the increased detection of colorectal polyps observed even after temporary use of low-dose aspirin indicates that non-molecular explanations for the antineoplastic effect of aspirin may exist and that the removal of polyps may play an important role. Second, the DNPR lacks data from endoscopy reports and we were thereby unable to investigate whether the polyps diagnosed in aspirin users actually bled or whether these polyps were found due to other causes. Third, the possibility of confounding by indication requires consideration. Confounding by indication may arise if cardiovascular ischaemic events initiated by atherosclerosis is related to the risk of colorectal polyps and CRC. ${ }^{70}$ Thus, overestimation of our risk estimates in new aspirin users could have occurred if the risk of colorectal neoplasms was a priori increased in aspirin users compared with non-users. Another concern is that acute myocardial infarction, stroke, atherosclerosis and CRC share risk factors such as smoking, obesity, metabolic syndrome and diabetes. Diet, exercise and other lifestyle-related risk factors also may play a role. The existing evidence has been conflicting, with some studies confirming an association between CRC and acute myocardial infarction/ stroke based on shared risk factors and other studies not detecting an association. ${ }^{71-78}$ We adjusted for comorbidities and comedication, which to some extent may have reduced potential cofounding from lifestyle-related risk factors. However, the conflicting results of previous studies need to be taken into account when interpreting our results.

In conclusion, our results indicate that use of lowdose aspirin might contribute to a lower risk of CRC by promoting bleeding from colorectal polyps and leading patients to undergo colonoscopy with polypectomy before CRC manifests. Results of previous studies indicate that several mechanisms may play a role in the inverse association between aspirin use and CRC risk. These should also be included when interpreting our results. Future studies are needed to assess the impact of aspirin dosage, treatment duration and intensity and further elucidate whether the increased bleeding in aspirin users stem from premalignant polyps or other sources

Contributors FST, DKF, RE and HTS contributed to the methodology of the study. FST, DKF, RE and HTS acquired the data. FST, RE and HTS directed the formal analyses, which were carried out by DKF. FST wrote the initial draft. All authors contributed to the discussion and interpretation of the results, which secured the intellectual content of the manuscript. All authors reviewed, edited and accepted the final version for submission, including the authorship list.

Funding Aarhus University. FST is supported by a scholarship from Aarhus University.

Competing interests None declared.

Patient consent for publication Not required.

Ethics approval The study was approved by the Danish Data Protection Agency (2016-051-000001) and is reported according to the PE-RECORD guidelines.

Provenance and peer review Not commissioned; externally peer reviewed. Data availability statement № data are available.

Open access This is an open access article distributed in accordance with the Creative Commons Attribution Non Commercial (CC BY-NC 4.0) license, which permits others to distribute, remix, adapt, build upon this work non-commercially, and license their derivative works on different terms, provided the original work is properly cited, appropriate credit is given, any changes made indicated, and the use is non-commercial. See: http://creativecommons.org/licenses/by-nc/4.0/.

\section{ORCID iDs}

Frederikke Schønfeldt Troelsen http://orcid.org/0000-0002-5276-5959

Dóra Körmendiné Farkas http://orcid.org/0000-0002-8577-048X

Rune Erichsen http://orcid.org/0000-0001-9398-9185

Henrik Toft Sørensen http://orcid.org/0000-0003-4299-7040

\section{REFERENCES}

1 Bray F, Ferlay J, Soerjomataram I, et al. Global cancer statistics 2018: GLOBOCAN estimates of incidence and mortality worldwide for 36 cancers in 185 countries. CA Cancer J Clin 2018;68:394-424.

2 Snover DC. Update on the serrated pathway to colorectal carcinoma. Hum Pathol 2011;42:1-10.

3 Erichsen R, Baron JA, Hamilton-Dutoit SJ, et al. Increased risk of colorectal cancer development among patients with serrated polyps. Gastroenterology 2016;150:895-902.

4 Crockett SD, Snover DC, Ahnen DJ, et al. Sessile serrated adenomas: an evidence-based guide to management. Clin Gastroenterol Hepatol 2015;13:11-26.

5 Jass JR. Classification of colorectal cancer based on correlation of clinical, morphological and molecular features. Histopathology 2007;50:113-30.

6 Rex DK, Rahmani EY, Haseman JH, et al. Relative sensitivity of colonoscopy and barium enema for detection of colorectal cancer in clinical practice. Gastroenterology 1997;112:17-23.

7 Winawer SJ, Zauber AG, Ho MN, et al. Prevention of colorectal cancer by colonoscopic polypectomy. The National Polyp study Workgroup. N Engl J Med 1993;329:1977-81. 
8 Friis S, Riis AH, Erichsen R, et al. Low-Dose aspirin or nonsteroidal anti-inflammatory drug use and colorectal cancer risk: a populationbased, case-control study. Ann Intern Med 2015;163:347-55.

9 Cuzick J, Thorat MA, Bosetti C, et al. Estimates of benefits and harms of prophylactic use of aspirin in the general population. Ann Oncol 2015;26:47-57.

10 Baron JA, Cole BF, Sandler RS, et al. A randomized trial of aspirin to prevent colorectal adenomas. N Engl J Med 2003;348:891-9.

11 Benamouzig R, Uzzan B, Deyra J, et al. Prevention by daily soluble aspirin of colorectal adenoma recurrence: 4-year results of the APACC randomised trial. Gut 2012;61:255-61.

12 Logan RFA, Grainge MJ, Shepherd VC, et al. Aspirin and folic acid for the prevention of recurrent colorectal adenomas. Gastroenterology 2008;134:29-38.

13 Sandler RS, Halabi S, Baron JA, et al. A randomized trial of aspirin to prevent colorectal adenomas in patients with previous colorectal cancer. N Engl J Med Overseas Ed 2003;348:883-90.

14 Burn J, Gerdes A-M, Macrae F, et al. Long-Term effect of aspirin on cancer risk in carriers of hereditary colorectal cancer: an analysis from the CAPP2 randomised controlled trial. Lancet 2011;378:2081-7.

15 Thun MJ, Jacobs EJ, Patrono C. The role of aspirin in cancer prevention. Nat Rev Clin Oncol 2012;9:259-67.

16 Wang $\mathrm{D}$, DuBois $\mathrm{RN}$. The role of anti-inflammatory drugs in colorectal cancer. Annu Rev Med 2013;64:131-44.

17 Schreuders EH, Ruco A, Rabeneck L, et al. Colorectal cancer screening: a global overview of existing programmes. Gut 2015;64:1637-49.

18 Halloran S, Launoy G, Zappa M. European guidelines for quality assurance in colorectal cancer screening and diagnosis. - first edition faecal occult blood testing. Endoscopy 2012;44:SE65-87.

19 Robertson DJ, Lee JK, Boland CR, et al. Recommendations on fecal immunochemical testing to screen for colorectal neoplasia: a consensus statement by the US Multi-Society Task force on colorectal cancer. Gastroenterology 2017;152:1217-37.

20 GBD 2016 Causes of Death Collaborators. Global, regional, and national age-sex specific mortality for 264 causes of death, 19802016: a systematic analysis for the global burden of disease study 2016. Lancet 2017;390:1151-210.

21 Zhou Y, Boudreau DM, Freedman AN. Trends in the use of aspirin and nonsteroidal anti-inflammatory drugs in the general U.S. population. Pharmacoepidemiol Drug Saf 2014;23:43-50.

22 McNeil JJ, Wolfe R, Woods RL, et al. Effect of aspirin on cardiovascular events and bleeding in the healthy elderly. $N$ Engl J Med 2018;379:1509-18.

23 Guirguis-Blake JM, Evans CV, Senger CA, et al. Aspirin for the primary prevention of cardiovascular events: a systematic evidence review for the U.S. preventive services Task force. Ann Intern Med 2016;164:804-13.

24 Capodanno D, Angiolillo DJ. Aspirin for primary cardiovascular risk prevention and beyond in diabetes mellitus. Circulation 2016;134:1579-94.

25 Lei $\mathrm{H}$, Gao Q, Liu S-R, et al. The benefit and safety of aspirin for primary prevention of ischemic stroke: a meta-analysis of randomized trials. Front Pharmacol 2016;7:440.

26 Bowman L, Mafham M, Wallendszus K, et al. Effects of aspirin for primary prevention in persons with diabetes mellitus. $N$ Engl $\mathrm{J}$ Med 2018;379:1529-39.

27 Brenner H, Tao S, Haug U. Low-Dose aspirin use and performance of immunochemical fecal occult blood tests. JAMA 2010;304:2513-20.

28 Sawhney MS, McDougall H, Nelson DB, et al. Fecal occult blood test in patients on low-dose aspirin, warfarin, clopidogrel, or nonsteroidal anti-inflammatory drugs. Dig Dis Sci 2010;55:1637-42.

29 Levi Z, Rozen P, Hazazi R, et al. Sensitivity, but not specificity, of a quantitative immunochemical fecal occult blood test for neoplasia is slightly increased by the use of low-dose aspirin, NSAIDs, and anticoagulants. Am J Gastroenterol 2009;104:933-8.

30 Clarke P, Jack F, Carey FA, et al. Medications with anticoagulant properties increase the likelihood of a negative colonoscopy in faecal occult blood test population screening. Colorectal Disease 2006;8:389-92.

31 Lee TJW, Hull MA, Rajasekhar PT, et al. Aspirin users attending for NHS bowel cancer screening have less colorectal neoplasia: chemoprevention or false-positive faecal occult blood testing? Digestion 2012;85:278-81.

32 Brenner H, Calderazzo S, Seufferlein T, et al. Effect of a single aspirin dose prior to fecal immunochemical testing on test sensitivity for detecting advanced colorectal neoplasms. JAMA 2019;321:1686-92.

33 Randel KR, Botteri E, Romstad KMK, et al. Effects of oral anticoagulants and aspirin on performance of fecal immunochemica tests in colorectal cancer screening. Gastroenterology 2019;156:1642-9.

34 Sorensen HT, Mellemkjaer L, Blot WJ, et al. Risk of upper gastrointestinal bleeding associated with use of low-dose aspirin. Am J Gastroenterol 2000;95:2218-24.

35 Chen W-C, Lin K-H, Huang Y-T, et al. The risk of lower gastrointestinal bleeding in low-dose aspirin users. Aliment Pharmacol Ther 2017;45:1542-50.

36 García Rodríguez LA, Martín-Pérez M, Hennekens $\mathrm{CH}$, et al. Bleeding risk with long-term low-dose aspirin: a systematic review of observational studies. PLoS One 2016;11:e0160046.

37 Pedersen CB. The Danish civil registration system. Scand J Public Health 2011;39:22-5

38 Schmidt M, Pedersen L, Sørensen HT. The Danish civil registration system as a tool in epidemiology. Eur J Epidemiol 2014;29:541-9.

39 Frank L. Epidemiology. when an entire country is a cohort. Science 2000;287:2398-9.

40 Schmidt M, Schmidt SAJ, Adelborg K, et al. The Danish health care system and epidemiological research: from health care contacts to database records]]\&gt. Clin Epidemiol 2019;11:563-91.

41 Johannesdottir SA, Horváth-Puhó E, Ehrenstein V, et al. Existing data sources for clinical epidemiology: the Danish national database of Reimbursed prescriptions. Clin Epidemiol 2012;4:303-13.

42 Schmidt M, Schmidt SAJ, Sandegaard JL, et al. The Danish national patient registry: a review of content, data quality, and research potential. Clin Epidemiol 2015;7:449-90.

43 Erichsen Ret al. Existing data sources for clinical epidemiology: the Danish national pathology registry and data bank. Clin Epidemiol 2010;2:51-6.

44 Gjerstorff ML. The Danish cancer registry. Scand J Public Health 2011;39:42-5.

45 Schmidt M, Hallas J, Friis S. Potential of prescription registries to capture individual-level use of aspirin and other nonsteroidal antiinflammatory drugs in Denmark: trends in utilization 1999-2012. Clin Epidemiol 2014;6:155-68.

46 Heide-Jørgensen U, Adelborg K, Kahlert J, et al. Sampling strategies for selecting general population comparison cohorts. Clin Epidemiol 2018;10:1325-37.

47 Bertero L, Massa F, Metovic J, et al. Eighth edition of the UICC classification of malignant tumours: an overview of the changes in the pathological TNM classification criteria-What has changed and why? Virchows Archiv 2018;472:519-31.

48 Thygesen SK, Christiansen CF, Christensen S, et al. The predictive value of ICD-10 diagnostic coding used to assess Charlson comorbidity index conditions in the population-based Danish national Registry of patients. BMC Med Res Methodol 2011;11:83.

49 Strate LL, Singh P, Boylan MR, et al. A prospective study of alcoho consumption and smoking and the risk of major gastrointestinal bleeding in men. PLoS One 2016;11:e0165278.

$50 \mathrm{He} \mathrm{E}$, Alison R, Blanks R, et al. Association of ten gastrointestinal and other medical conditions with positivity to faecal occult blood testing in routine screening: a large prospective study of women in England. Int J Epidemiol 2019;48:549-58

51 Lanas Ángel, Carrera-Lasfuentes P, Arguedas Y, et al. Risk of upper and lower gastrointestinal bleeding in patients taking nonsteroidal anti-inflammatory drugs, antiplatelet agents, or anticoagulants. Clin Gastroenterol Hepatol 2015;13:906-12.

52 Martinez Al, Freeman PR, Moga DC, et al. Statin use and gastrointestinal hemorrhage: a large retrospective cohort study. Am J Cardiovasc Drugs 2019;19:65-74.

53 Narum S, Westergren T, Klemp M. Corticosteroids and risk of gastrointestinal bleeding: a systematic review and meta-analysis. BMJ Open 2014;4:e004587.

$54 \mathrm{He}$ Y, Chan EW, Leung WK, et al. Systematic review with metaanalysis: the association between the use of calcium channel blockers and gastrointestinal bleeding. Aliment Pharmacol Ther 2015;41:1246-55.

55 Fagunwa IO, Loughrey MB, Coleman HG. Alcohol, smoking and the risk of premalignant and malignant colorectal neoplasms. Best Pract Res Clin Gastroenterol 2017;31:561-8.

56 Sørensen HT, Mellemkjaer L, Jepsen P, et al. Risk of cancer in patients hospitalized with fatty liver: a Danish cohort study. J Clin Gastroenterol 2003;36:356-9.

57 Chun EM, Kim SW, Lim SY. Prevalence of colorectal adenomatous polyps in patients with chronic obstructive pulmonary disease. Int $J$ Chron Obstruct Pulmon Dis 2015;10:955-60.

58 Jaruvongvanich V, Sanguankeo A, Wijarnpreecha K, et al. Risk of colorectal adenomas, advanced adenomas and cancer in patients with colonic diverticular disease: systematic review and metaanalysis. Digestive Endoscopy 2017;29:73-82. 
59 Blackett JW, Verna EC, Lebwohl B. Increased prevalence of colorectal adenomas in patients with nonalcoholic fatty liver disease: a cross-sectional study. Dig Dis 2020;38:1-9.

60 Miłek T, Forysiński K, Myrcha P, et al. Diabetes association of polyps and colon cancer. Pol Przegl Chir 2019;91:1-5.

61 Gartlehner G, Patel SV, Feltner C, et al. Hormone therapy for the primary prevention of chronic conditions in postmenopausal women: evidence report and systematic review for the US preventive services Task force. JAMA 2017;318:2234-49.

62 Dobrzycka M, Spychalski P, Łachiński AJ, et al. Statins and Colorectal Cancer - A Systematic Review. Exp Clin Endocrinol Diabetes 2020;128:255-62.

63 Cardel M, Jensen SM, Pottegård A, et al. Long-Term use of metformin and colorectal cancer risk in type II diabetics: a population-based case-control study. Cancer Med 2014;3:1458-66.

64 Makar GA, Holmes JH, Yang Y-X. Angiotensin-Converting enzyme inhibitor therapy and colorectal cancer risk. J Natl Cancer Inst 2014;106:djt374

65 Oakland K, Chadwick G, East JE, et al. Diagnosis and management of acute lower gastrointestinal bleeding: guidelines from the British Society of gastroenterology. Gut 2019;68:776-89.

66 Sengupta N, Cifu AS. Management of patients with acute lower gastrointestinal tract bleeding. JAMA 2018;320:86-7.

67 Troelsen FS, Farkas DK, Ording AG, et al. Prevalence of colorectal neoplasms and mortality in new users of low-dose aspirin with lower gastrointestinal bleeding. Am J Ther 2019. doi:10.1097/ MJT.0000000000001042. [Epub ahead of print: 25 Jul 2019]

68 Storm HH, Michelsen EV, Clemmensen IH, et al. The Danish cancer Registry-history, content, quality and use. Dan Med Bull 1997:44:535-9.
69 Viborg S, Søgaard KK, Farkas DK, et al. Lower gastrointestinal bleeding and risk of gastrointestinal cancer. Clin Trans/ Gastroenterol 2016; 7:e162.

70 Lee T-K, Chen Y-C, Kuo T-L. Comparison of the effect of acetylsalicylic acid on platelet function in male and female patients with ischemic stroke. Thromb Res 1987;47:295-304.

71 Chan AOO, Jim MH, Lam KF, et al. Prevalence of colorectal neoplasm among patients with newly diagnosed coronary artery disease. JAMA 2007;298:1412-9.

72 Erichsen R, Sværke C, Sørensen HT, et al. Risk of colorectal cancer in patients with acute myocardial infarction and stroke: a nationwide cohort study. Cancer Epidemiol Biomarkers Prev 2013;22:1994-9.

73 Chan AOO, Lam KF, Tong T, et al. Coexistence between colorectal cancer/adenoma and coronary artery disease: results from 1382 patients. Aliment Pharmacol Ther 2006;24:535-9.

$74 \mathrm{Kim}$ BJ, Kim JY, Chang DK, et al. Coexistence between carotid artery stenosis and colorectal adenomatous polyps in middle-aged men. Digestion 2010;81:20-6.

75 Watanabe $\mathrm{Y}$, Ozasa K, Ito Y, et al. Medical history of circulatory diseases and colorectal cancer death in the JACC study. J Epidemiol 2005;15 Suppl 2:S168-72.

76 Reicher-Reiss H, Jonas M, Goldbourt U, et al. Selectively increased risk of cancer in men with coronary heart disease. Am J Cardiol 2001;87:459-62. a6.

77 Robertson DJ, Riis AH, Friis S, et al. Neither long-term statin use nor atherosclerotic disease is associated with risk of colorectal cancer. Clin Gastroenterol Hepatol 2010;8:1056-61.

78 Dreyer L, Olsen JH. Cancer risk of patients discharged with acute myocardial infarct. Epidemiology 1998;9:178-83. 